\title{
Actinobacillus lignieresii
}

National Cancer Institute

\section{Source}

National Cancer Institute. Actinobacillus lignieresii. NCI Thesaurus. Code C86100.

A species of anaerobic, Gram negative, rod shaped bacteria assigned to the phylum Proteobacteria. This bacteria is nonmotile, catalase and oxidase positive, ferments sugars and is non hemolytic. A. lignieresii is part of the normal flora of the mucosa of the upper gastrointestinal tract and may cause tumorous abscesses in the tongue of cattle, sheep, horses, pigs and dogs. 